\title{
Respiratory health risks associated with workplaces located in roundabouts and outside of roundabouts along a road with high-traffic at Cotonou, Benin
}

\author{
Parfait Houngbégnon ${ }^{1,2,3}$, Afoussatou Amadou ${ }^{4}$, Hervé Lawin ${ }^{2}$, Eloïc Atindegla ${ }^{3}$, \\ Marius Kêdoté ${ }^{2}$, Benjamin Fayomi ${ }^{2}$, Simplice Dossou - gbété ${ }^{5}$, Victoire Agueh ${ }^{1}$ \\ 1. Institut Régional de Santé Publique, University of Abomey-Calavi \\ 2. EcoHealth Chair, Faculty of Health Sciences, University of Abomey-Calavi \\ 3. Institut de Recherche Clinique du Bénin \\ 4. Unité de Recherche en Microbiologie Appliquée et Pharmacologie des substances naturelles, University \\ of Abomey-Calavi \\ 5. Université de Pau et des pays de l'Adour
}

\begin{abstract}
OBJECTIVE: Air pollution is now a public health concern and there is an urgent need to find local feasible solution to overcome the related health issues. Regarding outdoor air pollution effect on vendors health and workplaces exposed to high traffic, it is important to accurately define the most exposed between those working along main roads or in roundabouts with high traffic. The purpose of this study was to assess the vendors respiratory health risks associated with these different geographical positions in Cotonou.
\end{abstract}

METHODS: A cross-sectional study was conducted and included all the shops along a main road and a roundabout with high traffic in Cotonou. One person was recruited per shop and was allocated a unique GPS data associated with the geographical position of its shop. Validated questionnaire on respiratory symptoms was administered to 194 individuals who were included.

RESULTS: The mean (standard deviation) of age of workers was $36.26( \pm 11.65)$ years and the sex ratio $(\mathrm{M} / \mathrm{F})$ was 1.8. Most of respondents (69.07\%) worked in non-ventilated rooms. $72.68 \%$ of the workers reported at least one respiratory symptom. This proportion was significantly different $(\mathrm{p}<0.001)$ between the subpopulations at roundabout (96.15\%) and apart from the roundabout (64.08\%). The most reported symptoms by the workers were respectively cough (47.94\%), itchy nose (42.27\%) and breathlessness (28.35\%). The risk of cough and itchy nose symptoms were respectively 5.15 (OR=5.15; 95\% $\mathrm{CI}=$ [2.21;12.04]; $\mathrm{p}<.001)$ and $3.44(\mathrm{OR}=3.44 ; 95 \% \mathrm{CI}=[1.55 ; 7.63] ; \mathrm{p}=0.002)$ higher in individuals working at the roundabout compared to those working along the main road.

CONCLUSION: Working in roundabout is associated with more respiratory disorders than practicing in shop along a main road. In a resources limited settings, it may be important to focus air pollution mitigation effort on this subpopulation of workers.

KEYWORDS: air pollution, high traffic, roundabouts, vendors, health risk, symptom. 


\section{INTRODUCTION}

Air pollution related to road traffic is a real challenge not only for health, but also for sustainable development and the reduction of environmental inequalities for most major urban areas. (Frère and al., 2005a). Living or have an occupational activity along a main road with high traffic is harmful for the health. Several studies have shown that living near a heavily trafficked road has significant risks to respiratory health (Brauer et al., 2003; Guéguen et al., 2012; Honoré et al., 2013; Karr et al., 2009; Zhou and Levy, 2006).

Industrialization and socio-economic situation in urban areas, local air pollution level is increasing and is leading to an increasing rate of mortality and morbidity (Elichegaray and al., 2009; Franck, 2010; Host and al., 2012). Several pollutants emitted into the atmosphere such as fine particulates (PM 2.5) are associated with respiratory diseases such as asthma, flu, etc.(Fourn and Fayomi, 2006; Host et al., 2012; Jeannée et al., 2006). The area of influence of these emissions, however, remains difficult to delimit. Knowledge of pollutant dispersal mechanisms at the street and neighborhood level is still incomplete (Franck, 2010; Host et al., 2012). Although air pollution is threat globally, it may differently affect people due to activities influencing locally their level of exposure. Working in a shop along a main road or in a roundabout with high traffic may lead to a different level of exposure in the workplace. The specificity of this geographical position is rarely taken into account in studies which mainly focused on comparison of health risk in people living or working along main roads and those living or working further away from main roads. The current study took into account this specificity when characterizing respiratory health risks in populations working near the road traffic.

\section{MATERIALS AND METHODS}

\section{Study site and population}

This study ran at Cotonou, main economic city of Benin. We have included all the shops that were located on the portion of road in figure 1 from point $A$ to point $C$ via point $B$. This portion of the road is $4.5 \mathrm{Km}$ long and the traffic is very high throughout the day because it serves the largest market in the city and the port of Cotonou. This road included the main roundabout of Cotonou which is represented on figure 2. One person per shop was included in the current study. When there was more than one person in the office, we interview the oldest one. It allowed us to associate at each respondent an unique GPS coordinates which is the GPS coordinates of his workplace. We interviewed 194 individuals. 


\section{Data collection}

A validated questionnaire https://www.ncbi.nlm.nih.gov/pubmed/30065166 on respiratory symptoms (cough, expectoration, wheezing, breathlessness, itchy nose) was administered to the study participants. The questionnaire also collected information on the ventilation of buildings, the duration of occupation, GPS coordinates and some socio demographic characteristics of the respondents. For data collection we developed an electronic case report form that integrate taking GPS coordinates. The data could thus be collected from the smart phones of the enumerators.

\section{Data analysis}

In the first part, we presented the socio demographic characteristics of the respondents and the frequency of respiratory symptoms. The test of chi-square or t-student were used to compare respectively proportion and mean in the two groups that are roundabout and outside the roundabout. The second part was devoted to the cartography of the different respiratory symptoms.

A logistic regression model was performed to assess the association between the occurrence of respiratory symptoms and the geographical location of participant's workplace (roundabout vs outside of roundabout). For the first model, the dependent variable was cough (presence or absence of symptom). For the second model, the dependent variable was itchy nose (presence or absence of symptom). The both models were adjusted on age, level of instruction, seniority on the site, and aeration of the occupied room. Analysis was performed using Stata software and p-value was considered significant when $\mathrm{p}$-value $<0.05$.

\section{RESULTS}

\section{Characteristics of respondents}

The characteristics of respondents are presented in table I. The sex ratio $(\mathrm{M} / \mathrm{F})$ was 1.8. It was 1.6 at roundabout against 1.8 outside the roundabout. The average age of respondents was $36.26 \pm 11.65$ years. There was no statistically significant difference between the two zones $(p=.38)$. The study population was predominantly educated $(86.6 \%)$. This situation was very different between the two groups. At roundabout, $36.54 \%$ of respondents had not attended school compared to only $4.93 \%$ among respondents outside the roundabout. The distribution of seniority at the place was significantly different between the two zones $(p<.001)$. At roundabout nearly half of the respondents had already more than 10 years of seniority at the place compared to only about $10 \%$ of those interviewed along the road. $69.07 \%$ of respondents worked in the building that were not well ventilated. (table I) 


\section{Prevalence of respiratory symptoms in relation to zones}

The proportion of each type of respiratory symptom is presented in table II.

$72.68 \%$ of respondents reported having at least one of the five respiratory symptoms. This proportion was significantly different $(\mathrm{p}<0.001)$ between the subpopulation at roundabout $(96.15 \%)$ and out the roundabout $(64.08 \%)$. The most reported symptoms by the respondents were respectively cough (47.94\%), itchy nose $(42.27 \%)$ and breathlessness $(28.35 \%)$. For each of the respiratory symptoms, the proportion was significantly higher at the roundabout than outside the roundabouts. (table II)

The figure 4 shows the spatial distribution of symptom of cough. (figure 4)

The multivariate logistic regression to estimate the risk of having a respiratory symptom at roundabout compared to outside the roundabout is presented in table III. (table III)

The results of logistic regression model showed that the presence of cough and itchy nose were high significantly associated with the place. The risk of cough symptoms was 5.15 higher in a person exercising at the roundabout compared to a person exercising along the road $(\mathrm{OR}=5.15 ; 95 \% \mathrm{CI}=$ [2.21;12.04]; $\mathrm{p}<.001)$. The risk of itchy nose symptoms was 3.44 higher in a person exercising at the roundabout compared to a person exercising along the $\operatorname{road}(\mathrm{OR}=3.44 ; 95 \% \mathrm{CI}=[1.55 ; 7.63] ; \mathrm{p}=.002)$.

\section{DISCUSSION}

During periods of low traffic, pollution levels are equivalent to the general atmosphere of the neighborhood where the axis is located. On the other hand, when the road traffic is important, to this general atmosphere is added the pollution directly induced by the traffic.(Host, 2013). Along the road traffic, it is observed a dispersion of pollutants which reduces the risk incurred by workers near road traffic. The three roundabouts of our study, were located downtown, most of the companies are in town, there is a strong traffic often observed in this area especially to the hours of return of the service. This result is consistent with that of $\mathrm{Wu}$ et al., (2005). The presence of traffic lights at roundabouts is an important factor in the health risk associated with air pollution. In peak areas, pollutants released into the air by motorcycles and vehicles create a fog effect in this area. As for stationed workers, their sales 
room serves as a receptacle for these pollutants in suspension. Hence a transfer of pollution from the outside to the inside of the premises (Ogouwale, 2010). These indicate that premises near traffic are likely to be more polluted than those located in an environment less directly influenced by pollution sources, although indoor pollution levels are also conditioned by ventilation and the indoor environment (Host et al., 2012). This study found that most rooms are not ventilated. This small opening will result in the lack of air exchange in the rooms. The compilation of pollutants in the rooms has an accumulating effect, resulting in a condensation of polluted air in them. Thus, in a study conducted in Helsinki and Amsterdam (Frère et al., 2005), it was estimated that $70 \%$ to $84 \%$ of some pollutants, measured indoors, came from outside (the internal source linked to smoking being absent in this study). The risk is increased for vendors near the traffic lights, often at roundabouts.

Age was not a determining factor in this study, especially since the minimum age is 25 years old. It should be noted that the women studied are of childbearing age and those who already have children, especially infants, these children remained in the same conditions. Studies have shown that in children living near high-traffic roads or in a dense road network, the health risk is very high because of their weak immune system(Frère et al., 2005; Hoffmann et al., 2006; Honoré et al., 2013; Shi et al., 2018). Increases in risk range from $20 \%$ to $100 \%$ depending on the health indicator, the exposure index and the population studied. Some authors stress that the very first years of life could constitute a critical window of exposure to atmospheric pollutants, with an implication in the genesis of asthma (Zmirou et al., 2004). These different results also illustrate the diversity of exposure indicators constructed from the remoteness and / or the intensity of road traffic, which make it difficult to directly compare the levels of risk obtained. Nevertheless, it appears overall that chronic exposure to pollutants related to road traffic is likely to have adverse effects on the respiratory health especially of children whose lungs are maturing. These results are confirmed by the study of a prospective cohort, in which an alteration of the maturation of the respiratory function between the age of 10 and 18 years was observed for children living under 500 meters from a highway(Gauderman et al., 2005). For adults, attacks on the respiratory system related to proximity to road traffic have also been highlighted. Thus, Lindgren et al. (2009) found an increased risk of $40 \%$ of asthma and $64 \%$ of chronic obstructive pulmonary disease in adults living within 100 meters of a road with a traffic intensity greater than 10 vehicles per minute. These results indicate that air pollution in areas under the direct influence of road traffic has specificities in terms of composition and levels of pollutants. (Panis et al., 2006)

Similarly, only the location of the seller has a direct effect on the degree of exposure to respiratory symptoms, especially since the risk is at least 3 times higher around roundabouts than along traffic. This confirms that roundabouts constitute an area with a high risk of local pollution. It was found that coughing and sneezing symptoms were significantly associated with the location of the workers. Zmirou et al., In 2004, showed through their study that the risk of developing asthma and respiratory 
symptoms such as exacerbation of asthma and infections is higher, depending on the location and the distance occupied from each other to road traffic(Zeger and Diggle, 2001 ; Zmirou et al., 2004). Cartographers have shown a decrease in ambient pollution as we move away from the core of the agglomeration where emissions are most intense; the gradient between the heart of the agglomeration and the periphery fades.

Characterization and measurement of population exposure to local emissions are difficult to establish (Reungoat et al., 2004). Epidemiological studies on the subject have thus often used indirect methods to account for these exposures, and if they have been able to demonstrate higher frequencies of respiratory diseases and symptoms, as well as higher risks of death related to these exposures traffic (Bayer-Oglesby et al., 2006; Brauer et al., 2003; Gauderman et al., 2005; Guéguen et al., 2012), it remains difficult to compare the results obtained in one area and apply them to another.

Further studies should be done for an assessment of local pollution in a wider area. Also, epidemiological studies will be made following this study to highlight the types of pollutants characterizing the study area, the consequences of these pollutants on the body regardless of the geographical position of workers on road traffic. These results should enable managers to make the necessary arrangements for the liberation of high-risk areas on road traffic or a reduction of the health impacts in these areas.

\section{CONCLUSION}

The profiles of decreasing pollution levels from the traffic lanes, as well as the phenomena of transfer from the outside to the interior are still poorly known. Thus, uncertainties persist regarding the levels of traffic-related pollutants found in these environments. Moreover, it is difficult to take into account the time spent in these different places to estimate an overall exposure.

These uncertainties in the measurement of global exposure to local air pollution, particularly due to the fact that potential travel-related exposures, which can be particularly high, are not taken into account, are likely to introduce a bias that could undermine the strength and precision of the true association between pollution and health. To reduce these uncertainties, "hybrid" models combining estimates of pollutant concentrations in different places of life and time spent in these environments should be developed.

Despite the limitations of the current indicators, whether based on distance contrasts or pollution levels, the results suggest an increased risk of occurrence or exacerbation of cardio-respiratory diseases for populations residing near sources important road traffic. Awareness will reduce these risks, ensure the best living conditions for the occupants of the tracks and promote human health. 
The current study showed that workplaces located at roundabout were more exposed to air pollution compared to workplaces along a main road. We have also demonstrated that workers in the roundabout more respiratory symptoms. In resources poor limited settings, this geographical position can be taken into account in the air pollution effect mitigation effect.

\section{BIBLIOGRAPHICAL REFERENCES}

Bayer-Oglesby, L., Schindler, C., Hazenkamp-von Arx, M.E., Braun-Fahrländer, C., Keidel, D., Rapp, R., Künzli, N., Braendli, O., Burdet, L., Sally Liu, L.-J., Leuenberger, P., Ackermann-Liebrich, U., the SAPALDIA Team, 2006. Living near Main Streets and Respiratory Symptoms in Adults. Am. J. Epidemiol. 164, 1190-1198. https://doi.org/10.1093/aje/kwj338

Boman, J., Lindén, J., Thorsson, S., Holmer, B., Eliasson, I., 2009. A tentative study of urban and suburban fine particles (PM2. 5) collected in Ouagadougou, Burkina Faso. X-Ray Spectrom. Int. J. 38, 354-362.

Brauer, M., Hoek, G., van Vliet, P., Meliefste, K., Fischer, P., Gehring, U., Heinrich, J., Cyrys, J., Bellander, T., Lewne, M., Brunekreef, B., 2003. Estimating Long-Term Average Particulate Air Pollution Concentrations: Application of Traffic Indicators and Geographic Information Systems: Epidemiology 14, 228-239. https://doi.org/10.1097/01.EDE.0000041910.49046.9B

Elichegaray, C., Bouallala, S., Maitre, A., Ba, M., 2009. État et évolution de la pollution atmosphérique. Rev. Mal. Respir. 26, 191-206.

Fourn, L., Fayomi, E.B., 2006. Pollution atmosphérique en milieu urbain à Cotonou et à Lokossa, Bénin. Bull Soc Pathol Exot 99, 264-268.

Franck, M., 2010. Diffusion spatiale de l'urbanisation et de l'industrialisation et formation d'une région urbaine: le cas de Surabaya, en Indonésie, in: Annales de Géographie. Armand Colin, pp. 6992.

Frère, S., Roussel, I., Blanchet, A., 2005. Les pollutions atmosphériques urbaines de proximité à l'heure du Développement Durable. Dév. Durable Territ. Économie Géographie Polit. Droit Sociol.

Gauderman, W.J., Avol, E., Lurmann, F., Kuenzli, N., Gilliland, F., Peters, J., McConnell, R., 2005. Childhood Asthma and Exposure to Traffic and Nitrogen Dioxide: Epidemiology 16, 737-743. https://doi.org/10.1097/01.ede.0000181308.51440.75

Gauvin, S., Reungoat, P., Cassadou, S., Dechenaux, J., Momas, I., Just, J., Zmirou, D., 2002. Contribution of indoor and outdoor environments to PM2. 5 personal exposure of childrenVESTA study. Sci. Total Environ. 297, 175-181.

Giugliano, M., Lonati, G., Butelli, P., Romele, L., Tardivo, R., Grosso, M., 2005. Fine particulate (PM2. 5-PM1) at urban sites with different traffic exposure. Atmos. Environ. 39, 2421-2431. 
Guéguen, F., Stille, P., Lahd Geagea, M., Perrone, T., Chabaux, F., 2012. Atmospheric pollution in an urban environment by tree bark biomonitoring - part II: $\mathrm{Sr}, \mathrm{Nd}$ and $\mathrm{Pb}$ isotopic tracing. Chemosphere 86, 641-647. https://doi.org/10.1016/j.chemosphere.2011.11.008

Havard, S., 2008. Contribution de la pollution atmosphérique aux inégalités socio-spatiales de santé: analyse écologique du risque d'infarctus du myocarde dans l'agglomération de Strasbourg (PhD Thesis). Université Rennes 1.

Hoffmann, B., Moebus, S., Stang, A., Beck, E.-M., Dragano, N., Mohlenkamp, S., Schmermund, A., Memmesheimer, M., Mann, K., Erbel, R., Jockel, K.-H., on behalf of the Heinz Nixdorf RECALL Study Investigative Group, 2006. Residence close to high traffic and prevalence of coronary heart disease. Eur. Heart J. 27, 2696-2702. https://doi.org/10.1093/eurheartj/ehl278

Honoré, C., Dugay, F., Pernot, P., 2013. Proximité au trafic routier et pollution de l'air en Ile-de-France. VertigO - Rev. Électronique En Sci. Environ. https://doi.org/10.4000/vertigo.12805

Host, S., 2013. Exposition à la pollution atmosphérique liée au trafic routier et risques sanitaires. VertigO - Rev. Électronique En Sci. Environ. https://doi.org/10.4000/vertigo.12816

Host, S., Chatignoux, E., Leal, C., Grémy, I., 2012. Exposition à la pollution atmosphérique de proximité liée au trafic: quelles méthodes pour quels risques sanitaires? Rev. DÉpidémiologie Santé Publique 60, 321-330.

Host, Sabine, Chatignoux, E., Saunal, A., 2012. Impacts sanitaires de la pollution atmosphérique urbaine et des expositions à proximité du trafic routier dans l'agglomération parisienne. Obs. Régional Santé Î--Fr.

Jeannée, N., Mosqueron, L., Nedellec, V., Elichegaray, C., Bouallala, S., Desqueyroux, H., Guillaume, B., Liousse, C., Lagache, R., 2006. Évaluation de l'exposition en zones urbaines à la pollution atmosphérique: méthodes existantes et application aux PM10 en France métropolitaine. 22683798.

Karr, C.J., Rudra, C.B., Miller, K.A., Gould, T.R., Larson, T., Sathyanarayana, S., Koenig, J.Q., 2009. Infant exposure to fine particulate matter and traffic and risk of hospitalization for RSV bronchiolitis in a region with lower ambient air pollution. Environ. Res. 109, 321-327. https://doi.org/10.1016/j.envres.2008.11.006

Ogouwalé, 2010. Stratégies de lutte contre la pollution atmosphérique dans la ville de Cotonou (Bénin).

Panis, L.I., Broekx, S., Liu, R., 2006. Modelling instantaneous traffic emission and the influence of traffic speed limits. Sci. Total Environ. 371, 270-285.

Shi, C., Yuan, R., Wu, B., Meng, Y., Zhang, Hao, Zhang, Hongqun, Gong, Z., 2018. Meteorological conditions conducive to PM2.5 pollution in winter 2016/2017 in the Western Yangtze River Delta, China. Sci. Total Environ. 642, 1221-1232. https://doi.org/10.1016/j.scitotenv.2018.06.137 
Sørensen, M., Daneshvar, B., Hansen, M., Dragsted, L.O., Hertel, O., Knudsen, L., Loft, S., 2003. Personal PM2. 5 exposure and markers of oxidative stress in blood. Environ. Health Perspect. $111,161$.

Wu, J., Lurmann, F., Winer, A., Lu, R., Turco, R., Funk, T., 2005. Development of an individual exposure model for application to the Southern California children's health study. Atmos. Environ. 39, 259-273. https://doi.org/10.1016/j.atmosenv.2004.09.061

Zeger, S.L., Diggle, P.J., 2001. Correction: Exposure Measurement Error in Time-Series Air Pollution Studies. Environ. Health Perspect. 109, a517-a517. https://doi.org/10.1289/ehp.109-a517a

Zhou, Y., Levy, J., 2006. Factors Influencing the Spatial Extent of Mobile Source Air Pollution Impacts: a Review: Epidemiology 17, S468. https://doi.org/10.1097/00001648-200611001-01258 